\title{
Normas para autores
}

CUHSO utiliza como normas bibliográficas y de presentación de manuscritos las normas APA, sexta edición, que pueden ser consultada aquí: <apastyle.org>.

- Los artículos deben ser presentados en letra Verdana, tamaño número I 2, a espacio simple.

- CUHSO promueve la utilización de estándares abiertos. Los artículos serán recibidos preferentemente en formato ODT (procesadores como Libre Office u Open Office). También se aceptan el formato Doc (Microsoft Word).

- Se aceptan artículos en inglés, portugués y español.

\section{Tipos de manuscritos recibidos}

- Artículos en que se presenten resultados de investigación. Deben incluir una introducción, el cuerpo del texto y conclusión. Debe incluir problema de investigación, hipótesis o preguntas de investigación y presentación de resultados. Serán sometidos a revisión de pares e indexados. Extensión entre 8.000 a I 2.000 palabras.

- Artículos en que se presenten adelantos de trabajos de investigación en curso. Deben incluir una introducción, el cuerpo del texto y conclusión. Deben incluir propuesta de investigación y, cuando corresponda, presentación de resultados preliminares. Serán sometidos a revisión de pares e indexados. Extensión entre 4.000 a 8.000 palabras.

- Textos en que se presenten discusiones teóricas actuales sobre tópicos específicos de las ciencias sociales y humanidades o en que se haga una revisión de aspectos específicos de la obra completa de uno o más autores. Deben incluir introducción, cuerpo del texto y conclusión. Serán sometidos a revisión de pares e indexados. Extensión entre 8.000 y I 5.000 palabras.

- Reseñas de libros en que se comenten publicaciones recientes y relevantes de las ciencias sociales y humanidades, la estructura de presentación 
es libre. Estas publicaciones no son sometidas a revisión de pares, ni indexadas. Extensión entre I.000 y 2.000 palabras.

\section{Estructura del manuscrito}

- Las páginas no deben estar numeradas.

- Todos los tipos de artículo deben incluir una portadilla con el título del manuscrito. En el caso del texto para revisión, debe ser entregado en una versión anónima; en la versión aprobada para publicación se debe indicar nombre del autor y filiación institucional.

- No se publicarán trabajos del mismo autor en números consecutivos.

- El documento presentado a evaluación no debe contener ninguna referencia al autor, deben ser borrados los datos de firma digital del artículo, así como cualquier referencia que lo identifique como la autocita, por ejemplo, "como discutió el autor», "como expresé en otro momento", etcétera. Se puede citar a sí mismo en tercera persona.

- En la siguiente página debe escribirse un abstract de entre 300 a 400 palabras, e incluir hasta cuatro palabras claves. Resumen y palabras claves deben ser presentados en español e inglés (la versión en inglés sólo en caso de versión aprobada o aprobada con correcciones). El resumen debe incluir presentación del problema, propuesta teórica y/o metodológica, según corresponda, y principales resultados y/o conclusiones.

- Cuadros, tablas y citas de más de 40 palabras se deben presentar con un espaciado adicional antes y después.

- A continuación debe presentarse el manuscrito con hasta cuatro niveles de encabezados siguiendo lo estipulado por las normas APA. I) Título del manuscrito: centrado y mayúsculas; 2) título de sección: centrado, altas y bajas; 3) primer nivel de subtítulos: cursivas, altas y bajas, centrado; 4) segundo nivel de subtítulos: cursivas, altas y bajas, alineado a la izquierda; tal como se muestra a continuación:

TÍTULO DEL MANUSCRITO

Título de sección

Primer nivel de subtítulos

Segundo nivel de subtítulos 


\section{Citación y referencias}

Las referencias a autores se efectuarán en el texto siguiendo lo estipulado por las normas APA, sexta edición:

- Trabajo de un solo autor: Pérez (2000), como señala Pérez (2000), en el 2000 Pérez señaló.

- Si un trabajo tiene dos autores deben ser nombrados los dos siguiendo las mismas normas de cita del primer punto.

- Cuando son tres o más autores, cítelos a todos la primera vez y si es necesario citarlos nuevamente, cite al primer autor seguido de la expresión «y otros».

- Cuando cite a una organización, utilice el nombre completo y entre paréntesis la abreviación; en las siguientes citas, sólo utilice la abreviación.

- Si cita a dos autores con el mismo apellido, debe diferenciarlos a lo largo de todo el texto con sus iniciales: Pérez, José (2009) y Pérez, Homero (2010).

- Citas textuales de menos de 40 palabras se colocan en el mismo texto entre comillas, citas de más de 40 palabras se inician en párrafo aparte, con una tabulación adicional de ( $\mathrm{I}, 5 \mathrm{cms}$.).

- En las citas textuales indique siempre el año de publicación y número de página (Pérez, 2010: 68). 